\title{
Nutrição mineral do cafeeiro e qualidade da bebida
}

\author{
Herminia Emilia Prieto Martinez, Júnia Maria Clemente², José Soares de Lacerda \\ Yonara Poltronieri Neves ${ }^{4}$, Adriene Woods Pedrosa ${ }^{5}$ \\ http://dx.doi.org/10.1590/0034-737X201461000009
}

\begin{abstract}
RESUMO
Os nutrientes minerais interferem na qualidade final do café por duas vias, uma direta, por seu papel no metabolismo da planta e acúmulo de compostos químicos desejáveis, do ponto de vista do aroma e sabor do café, e, outra, indireta, por seu papel na produção de compostos que desfavorecem o desenvolvimento microbiano nos grãos. Neste trabalho, procurou-se destacar as características químicas dos grãos associadas à qualidade da bebida e suas possíveis interações com os macro e micronutrientes, bem como relatar os resultados de pesquisa que relacionam nutrição mineral, qualidade da bebida e produção de compostos a ela associados.
\end{abstract}

Palavras-chave: Coffea arabica L., nutrição mineral, qualidade.

\begin{abstract}
\section{Coffee mineral nutrition and beverage quality}

Mineral nutrients influence the final quality of coffee in two ways: first directly, for their functions in plant metabolism and accumulation of desirable chemical compounds from the standpoint of flavor and taste of coffee; and indirectly, for its role in producing compounds that are harmful to microbial growth in beans. In this study, we focused on the chemical compounds of green coffee related to good beverage quality and its possible interactions with macro and micronutrients. We also report research findings that relate mineral nutrition, beverage quality and production of compounds in coffee beans.
\end{abstract}

Key words: Coffea arabica L., mineral nutrition, coffee quality.

Recebido para publicação em 15/05/2014 e aprovado em 11/10/2014.

${ }^{1}$ Engenheira-Agrônoma, Doutora. Departamento de Fitotecnia, Universidade Federal de Viçosa, Campus Viçosa, Avenida Peter Henry Rolfs, s/n, 36570-000, Viçosa, Minas Gerais, Brasil. herminia@ufv.br (autora para correspondência).

${ }^{2}$ Engenheira-Agrônoma, Doutora. Universidade Federal de Viçosa, Campus Rio Paranaíba, Rodovia MG-230, Km 7, 38810-000, Rio Paranaíba, Minas Gerais, Brasil. junia.clemente@yahoo.com.br

${ }^{3}$ Engenheiro-Agrônomo, Mestre. Departamento de Fitotecnia, Universidade Federal de Viçosa, Campus Viçosa, Avenida Peter Henry Rolfs, s/n, 36570-000, Viçosa, Minas Gerais, Brasil. j_s_lacerda@hotmail.com

${ }^{4}$ Engenheira-Agrônoma, Doutora. Empresa de Pesquisa Agropecuária de Minas Gerais, Unidade regional Zona da Mata, Campus Viçosa, Vila Gianetti, casas 46 e 47, $36570-000$, Viçosa, Minas Gerais, Brasil. ypoltronieri@epamig.br

${ }^{5}$ Engenheira-Agrônoma, Doutora. University of Nebrasca, 137, Keim Hall, Room 125, 68583-0937, Lincoln, Nebraska, Estados Unidos da América do Norte (CAPES/USDA). awoods@ pop.com.br 


\section{INTRODUÇÃO}

A qualidade do café, atributo que tem o maior peso na determinação do preço e comercialização, pode ser definida como um conjunto de características físicas, químicas, sensoriais e de segurança que atendem os gostos dos diversos tipos de consumidores (Brasil, 2003; Simões et al., 2008). De acordo com Amorim (1978), ela depende de vários fatores, entre eles a composição química do grão, que é determinada não só geneticamente, mas também por sistema de cultivo, época de colheita, preparo, armazenamento e torração.

No Brasil, a classificação do café quanto à qualidade é feita por duas maneiras: 1) contagem de grãos defeituosos, pretos, ardidos, verdes, pretos-verdes, brocados, quebrados e mal granados e presença de impurezas como cascas, gravetos e torrões de terra. Dessa avaliação, resulta a classificação do café em tipos que vão de 2 a 8 , sendo o tipo 4 considerado como padrão ou base; 2 ) descrição de atributos relacionados com a qualidade, como tamanho, uniformidade da seca, coloração do grão cru e torrado, destacando-se a prova de xícara, realizada por degustadores experientes. A prova de xícara resulta em classificação do paladar da bebida em estritamente mole, mole, apenas mole, duro, riado, rio e rio zona, sendo os três últimos inaceitáveis.

Paralelamente, existem sistemas numéricos de classificação, como o usado pela Associação Brasileira de Cafés Especiais (BSCA), que levam em conta os atributos, em vez dos defeitos, com valor máximo de 100. Nesse sistema, consideram-se os atributos bebida limpa, doçura, acidez, corpo, sabor, gosto remanescente, balanço ou equilíbrio e nota geral. Cada atributo recebe uma nota variável de 0 a 8 , à qual somam-se 36 pontos para obter a nota geral. Os cafés que alcançam nota acima de 80 são classificados como cafés gourmets ou especiais e conseguem preços de 40 a $80 \%$ superiores. Notas entre 71 e 75 são atribuídas à bebida dura limpa, de 75 a 79 para bebida apenas mole, de 80 a 84 para bebida mole e acima de 85 para bebida estritamente mole (Dalvi, 2011).

Comparativamente a outras espécies de Coffea, a bebida de Coffea arábica, por ser suave e delicada, é preferida. Por essa razão, num primeiro momento, o melhoramento do cafeeiro por meio de hibridações inter e intraespecíficas foi direcionado preferencialmente para obter redução de porte, produtividade, resistência a doenças e nematoides. No entanto, a composição química e as propriedades organolépticas variam tanto entre como dentro de espécies, e, ganhos genéticos, para qualidade, podem ser conseguidos mediante estratégias de melhoramento. Há híbridos interespecíficos de $C$. arábica com C. canephora Pierre ex A. Froehner, $C$. congensis A. Froehner e C. liberica Hilm, que apresen- tam boa qualidade da bebida. Valores significativos de ganhos genéticos para tamanho do grão, teor de cafeína, qualidade da bebida e tempo de maturação também foram obtidos (Leroy, et al., 2006).

As composições químicas médias dos grãos crus de C. arabica, C. canephora, C. congensis, C. eugenioides S. Moore, C. racemosa Lour. e C. kapakata (A. Chev.) Bridson são apresentadas na Tabela 1.

A matéria-prima para a obtenção de um café de boa qualidade é o grão completamente desenvolvido, sem danos de qualquer ordem e maduro.

Com relação à maturação, o fruto do cafeeiro é climatério, ou seja, sua maturação inicia-se com o aumento da atividade respiratória, após anterior queda, no final do período de crescimento. Essa atividade respiratória aumentada, "climatério respiratório", estende-se por vários dias (Taiz \& Zeiger, 2004).

O gatilho do climatério respiratório é o aumento da produção de ACC-oxidase e a consequente síntese de etileno endógeno, que incrementa a respiração e a síntese de enzimas. Esses eventos afetam o metabolismo de açúcares e ácidos, promovem degradação da clorofila e aumento da síntese de carotenoides, antocianinas e antocianidinas, flavonoides que darão coloração aos frutos (Taiz \& Zeiger, 2004; Rodrigues \& Ono, 2001).

As mudanças acima relacionadas ocorrem por ação da chalcona sintetase, que é ativada pela ação do etileno. O etileno ativa, também, a polifenoloxidase, que em concentrações elevadas reduz a concentração de ácidos fenólicos e melhora o sabor. Sob a ação do etileno há, ainda, aumento da concentração de poligalacturonase, celulase, pectina metil esterase e $\beta-1-3$ glucanase, responsáveis pela redução da rigidez da parede celular, além da redução da concentração de poliaminas no fruto. Ocorre decréscimo de adstringência e síntese de compostos voláteis, como aldeídos, ésteres, cetonas e álcoois, que caracterizam o aroma do fruto maduro (Carvalho \& Chalfoun, 1985; Rodrigues \& Ono, 2001; Taiz \& Zeiger, 2004).

Após o amadurecimento total, os frutos entram em um período de senescência, com escurecimento da casca e da polpa em razão, da oxidação dos pigmentos, transformando-se em passas e boias, com o avanço do processo de secagem. Nesse período, podem ocorrer fermentações e até mesmo podridões, com produção de álcoois e ácidos indesejáveis, que afetarão a qualidade dos grãos beneficiados (Carvalho \& Chalfoun, 1985).

A incidência de micro-organismos nas fases de pré e pós-colheita tem sido um dos principais fatores que influenciam a qualidade do café. Os frutos estão expostos a uma diversidade de micro-organismos, tais como leveduras, fungos, bactérias, que, encontrando condições favoráveis para se desenvolverem, infectam os grãos. Dentre estes, os fungos filamentosos são os 
que podem causar maior dano e comprometer a qualidade (Carvalho,1997). Simões (2009) relata que fungos dos gêneros Colletotrichum, Fusarium, Penicillium, Cladosporium e Aspergillus são os mais abundantes durante o processamento do café, sendo que Aspergillus e Pennicillium são potenciais produtores de micotoxinas.

Além da influência direta na qualidade, promovida pela ação de fungos, as micotoxinas são metabólitos secundários altamente nocivos à saúde do homem. No café, a de maior ocorrência é a Ocratoxina, produzida por fungos dos gêneros Aspergilus e Penicillium. Dentre os fatores que favorecem o desenvolvimento fúngico destacam-se temperatura, umidade relativa, conteúdo de umidade, predomínio de linhagens toxigênicas, composição do substrato e competição microbiana. Os fungos degradam paredes e membranas e alteram a coloração do grão. Degradam polissacarídeos a álcoois, ácido acético, lático, propiônico, butírico e outros ácidos carboxílicos. O fungo Aspergilus niger produz o halocomposto 2, 4, 6 tricloroanisol, que confere sabor amargo à bebida (Alves, 1996) e, juntamente com o 2, 4, 6 triclorofenol, caracteriza a bebida "rio" (Vidal, 2001).

De acordo com Marschner (2012), a resistência das plantas a pragas e doenças pode ser aumentada por mudanças na anatomia ou em propriedades fisiológicas. No primeiro caso, células epidérmicas mais grossas e um maior grau de lignificação ou silificação podem representar vantagens adaptativas, por dificultarem a infecção. No segundo, a síntese de substâncias repelentes ou inibitórias (fitoalexinas) pode alterar as respostas das plantas aos ataques de parasitas. De modo geral, a germinação de esporos nos tecidos é estimulada pela pre- sença de exudados. A taxa de fluxo e a composição desses exudados dependem de sua concentração nas células e do gradiente de difusão. As concentrações de aminoácidos desses exudados podem ser particularmente altas quando o suprimento de $\mathrm{N}$ é excessivo, ou quando o de K é baixo. Em deficiência de K, a síntese de compostos de alto peso molecular, como amido, proteínas e celulose, é inibida, havendo acúmulo de compostos orgânicos de baixo peso molecular. Por outro lado, a difusão dessas substâncias para o apoplasto depende da permeabilidade das membranas, que é, consideravelmente, afetada por $\mathrm{Ca}$ e B.

O cálcio ligado como pectato é essencial para a resistência das paredes celulares e dos tecidos. A degradação de pectatos de cálcio é mediada por poligalacturonase, que é drasticamente inibida por altas concentrações de cálcio. A proporção de pectato de cálcio nas paredes celulares é importante para a susceptibilidade dos tecidos a infecções fúngicas e bacterianas e para o amadurecimento dos frutos. Muitos fungos invadem o apoplasto, liberando enzimas pectolíticas, que dissolvem a lamela média, mas que são drasticamente inibidas por $\mathrm{Ca}$ e, muitas vezes, um pequeno aumento no nível de cálcio dos frutos é suficiente para prevenir ou reduzir perdas econômicas causadas por podridões ocorridas no armazenamento (Marschner, 2012).

Porém, se as barreiras à penetração dos patógenos falham, após a ocorrência da infecção, rotas metabólicas secundárias podem ser ativadas produzindo fitoalexinas que se acumulam ao redor dos sítios de infecção e impedem o desenvolvimento dos patógenos, sendo que $\mathrm{Mn}, \mathrm{Fe}, \mathrm{Cu}$ e B podem estar envolvidos nesses mecanismos de defesa (Pozza et al., 2004).

Tabela 1. Composição química dos grãos de café crus

\begin{tabular}{|c|c|c|c|c|c|c|c|}
\hline Componentes & $\begin{array}{c}\text { Coffea } \\
\text { arabica }\end{array}$ & $\begin{array}{c}\text { Coffea } \\
\text { canephora }\end{array}$ & $\begin{array}{c}\text { Coffea } \\
\text { liberica }\end{array}$ & $\begin{array}{c}\text { Coffea } \\
\text { congensis }\end{array}$ & $\begin{array}{c}\text { Coffea } \\
\text { eugenioides }\end{array}$ & $\begin{array}{c}\text { Coffea } \\
\text { racemosa }\end{array}$ & $\begin{array}{c}\text { Coffea } \\
\text { kapakata }\end{array}$ \\
\hline Cafeína & 1,2 & 2,2 & 0,46 & 2,03 & 0,93 & 1,27 & 1,13 \\
\hline Trigonelina & 1,0 & 0,7 & 0,5 & 1,33 & 1,88 & 1,33 & 2,15 \\
\hline Cinzas $(41 \%$ de $\mathrm{K})$ & 4,2 & 4,4 & - & - & - & - & - \\
\hline \multicolumn{8}{|l|}{ Ácidos: } \\
\hline Clorogênico total & 6,5 & 10,0 & 3,29 & 4,86 & 4,76 & 4,43 & 4,09 \\
\hline Alifáticos & 1,0 & 1,0 & - & - & - & - & - \\
\hline Quínico & 0,4 & 0,4 & - & - & - & - & - \\
\hline Açúcares: & & & 26,42 & 27,94 & 24,91 & 27,24 & 27,24 \\
\hline Sacarose & 8,0 & 4,0 & - & - & - & - & - \\
\hline Redutores & 0,1 & 0,4 & - & - & - & - & - \\
\hline Polissacarídeos & 44,0 & 48,0 & - & - & - & - & - \\
\hline Lignina & 3,0 & 3,0 & - & - & - & - & - \\
\hline Pectina & 2,0 & 2,0 & - & - & - & - & - \\
\hline Proteína & 11,0 & 11,0 & - & - & - & - & - \\
\hline Aminoácidos & 0,5 & 0,8 & - & - & - & - & - \\
\hline Lipídeos & 16,0 & 10,0 & 13,75 & 10,69 & 16,75 & 11,32 & 16,05 \\
\hline
\end{tabular}

Valores expressos em g.100g-1 em base seca. Fonte: Monteiro \& Trugo (2005), Aguiar (2005). 
Sendo assim, os nutrientes minerais interferirão na qualidade final do café por duas vias, uma direta, por seu papel no metabolismo da planta e acúmulo de compostos químicos desejáveis do ponto de vista do aroma e sabor do café, e outra indireta, por seu papel na produção de compostos que desfavorecem o desenvolvimento microbiano nos grãos.

\section{CARACTERÍSTICAS QUÍMICAS DOS GRÃOS ASSOCIADAS À QUALIDADE DA BEBIDA}

O flavor e o aroma do café desenvolvem-se durante a torra e têm uma química muito complexa, que envolve centenas de reações simultâneas. Nela ocorrem as reações de Maillard e Strecker, degradação de proteínas, polissacarídeos, trigonelina e ácidos clorogênicos (Franca et al., 2005).

A torra compreende três estádios consecutivos: secagem, pirólise e resfriamento. No primeiro, ocorre perda de massa, causada pela lenta liberação de água e substâncias voláteis. O grão muda de cor, passando de azul esverdeado para amarelo. No segundo, a pirólise resulta em consideráveis mudanças nas propriedades físicas e químicas dos grãos. São liberadas grandes quantidades de água, substâncias voláteis e $\mathrm{CO}_{2}$ e os grãos tornam-se marrons, por causa da caramelização dos açúcares. Ao atingir esse ponto, o resfriamento é necessário para evitar-se a carbonização. De acordo com VargasElias (2011), a perda de massa é de $20 \%$, na torra escura, e chega a $14 \%$, na torra suave. A umidade dos grãos cai de $11-12 \%$ b.u. para $2,5-4,0 \%$ b.u. O mesmo autor relata que temperaturas a partir de $284{ }^{\circ} \mathrm{C}$, no torrefador, com tempos entre 9 e 16 minutos, permitiram o desenvolvimento de acidez, doçura e corpo em níveis ótimos, mantendo-se a percepção de adstringência em níveis mínimos.

\section{Açúcares}

O café apresenta de 5 a $10 \%$ de açúcares totais. Dentre os oligossacarídeos, a sacarose (não redutor) ocorre nos grãos de café em concentrações que variam de 5,1 a $9,4 \%$, no fruto maduro (Clifford \& Wilson, 1985). Na torra, a sacarose degrada-se, dando açúcares menores precursores de ácidos e aldeídos, responsáveis pelo flavor. Dentre os monossacarídeos, destacam-se a glicose e a frutose (redutores), com teores que variam de 0 a $0,5 \%$. Chagas (1994) associou, positivamente, os teores de açúcares redutores e não redutores à qualidade. Mazzafera (1999) encontrou menores concentrações de sacarose nos grãos defeituosos.

De acordo com Pinto et al. (2002), as melhores bebidas, com paladar estritamente mole, mole, apenas mole e duro apresentaram maiores teores de sólidos solúveis totais, o que é desejável tanto pelo ponto de vista do rendimento industrial como pela contribuição para assegurar corpo à bebida, que é importante para o café expresso. Alves (2009) verificou forte correlação entre qualidade da bebida e grau brix dos frutos maduros, sendo que $95 \%$ dos cafés que alcançaram nota superior a 80 apresentavam grau brix superior a 20 no momento da colheita.

\section{Trigonelina}

A trigonelina, N-metil betaína, ou ácido piridino-3carboxílico, é um composto relacionado com a cafeína. Sua degradação pelo calor resulta em niacina, nicotinamida e larga faixa de compostos voláteis, que incluem piridinas e o N-metilpirrol, os quais dão aroma ao café (Clifford \& Wilson, 1985). Durante a torrefação, a trigonelina sofre desmetilação, para formar niacina, uma vitamina importante para o metabolismo humano, em quantidades que podem chegar a $20 \mathrm{mg} 100 \mathrm{~g}^{-1}$ de café torrado. $\mathrm{O}$ conteúdo de trigonelina presente em amostras de café torrado vai depender do binômio tempo e temperatura de torrefação. Quanto mais drástico o processo de torrefação, serão encontrados na amostra menores teores de trigonelina (Monteiro e Trugo, 2005). Por essa razão, a associação entre teor de trigonelina e qualidade não é tão evidente nos grãos torrados; no entanto, de acordo com Farah et al. (2006), para os grãos crus, houve forte correlação negativa entre teor de trigonelinas e baixa qualidade $(r=-0,93)$ e entre teor de trigonelinas e sabor riado $(r=-0,94)$.

\section{Cafeína}

A cafeína é um derivado das xantinas, que confere sabor amargo e é importante para o flavor do café. As concentrações de cafeína e trigonelina em grãos crus e torrados têm sido positivamente associadas à qualidade do café (Franca et al., 2005, Farah et al., 2006). Segundo Farah et al. (2006), a bebida de paladar mole apresentou $1,26 \pm 0,06 \mathrm{~g} / 100 \mathrm{~g}$, enquanto a de paladar duro apresentou 0,96 $\pm 0,01 \mathrm{~g} / 100 \mathrm{~g}$ de cafeína.

A cafeína é um composto do metabolismo secundário, derivado de aminoácidos aromáticos (triptofano e tirosina), os quais são derivados do ácido chiquímico ou de aminoácidos alifáticos (ornitina, lisina). Esses compostos apresentam pelo menos um átomo de $\mathrm{N}$ em seu anel e têm caráter alcalino (Clifford \& Wilson, 1985).

A cafeína é uma purina (1,3,7-trimetilxantina), derivada de aminoácidos como glicina, ácido L-aspártico e L-glutamina. Seu precursor é a teobromina. Três N, metil transferases estão envolvidas na biossíntese da cafeína, entre elas estão a teobromina sintase e a cafeína sintase, as quais adicionam grupos metil à xantosina, para convertê-la em cafeína. Além das metilações, um dos 
passos da biossíntese da cafeína envolve a remoção de um resíduo de ribose (Clifford \& Wilson, 1985). Os genes que codificam as N-metiltransferases já foram isolados e podem ser usados para a produção de plantas com níveis alterados de cafeína (Ashihara, 2006). Ocorre na semente, livre no citoplasma e ligada à parede celular. A torra promove volatilização de cerca de $10 \%$ da cafeína, mas, por causa da concomitante perda de peso que ocorre no processo, sua concentração no grão torrado tende a aumentar. Esse comportamento não pode, entretanto, ser generalizado. Siqueira \& Abreu (2006) relatam que, após a realização da torra clara e média, houve diminuição dos teores de cafeína nos grãos. Numa xícara de café, o teor de cafeína varia de 40 a 160 mg.

\section{Compostos fenólicos}

Os compostos fenólicos são encontrados em ampla gama de alimentos vegetais, comumente consumidos, como frutas, cereais, hortaliças e bebidas de origem vegetal, como vinho, chá e café (Cheynier, 2005; Manach et al., 2004). Os ácidos clorogênicos são os principais compostos fenólicos não voláteis encontrados no café e representam de 6 a $12 \%$ de sua massa seca. Dentre estes, o principal subgrupo corresponde ao dos ácidos cafeoilquínicos (CQA), dicafeoilquínicos (di-CQA) e feruloilquínicos (Franca et al., 2005).

Os ácidos clorogênicos dão pigmentação, aroma e adstringência à bebida (Franca et al., 2005). A sensação de adstringência deriva da precipitação de proteínas e glicoproteínas salivares que servem como lubrificantes. Dentro de limites aceitáveis, exercem efeito positivo por darem "corpo à bebida". São um conjunto de cinco grupos principais de compostos fenólicos e seus isômeros, formados principalmente pela esterificação do ácido quínico, com um dos seguintes ácidos derivados do ácido cinâmico: o ácido cafeico, o ferúlico ou o p-coumárico. Estes grupos são ácidos cafeoilquínicos, com três isômeros principais (3, 4 e 5); os ácidos dicafeoilquínicos, cujos isômeros principais são 3,4; 3,5; 4,5; ácidos feruloilquínicos $(3,4,5)$; ácidos p-cumaroilquínicos e os ácidos cafeoilferuloilquínicos. Ocorrem na superfície dos grãos associados com graxa cuticular, ao lado da parede celular no endosperma e no citoplasma (Monteiro e Trugo 2005).

Durante o processo de torrefação, esses compostos fenólicos são intensamente degradados, originando pigmentos e componentes voláteis do aroma, como fenol e vinilguaiacol. Podem ocorrer perdas de até $90 \%$ do conteúdo total de ácidos clorogênicos após a torrefação severa dos grãos (Monteiro \& Trugo, 2005). Entretanto, quando realizadas torra clara e média, a percentagem de ácidos clorogênicos em grãos naturais, descascados e despolpados, pode aumentar (Siqueira \& Abreu, 2006). Cerca de 50\% do conteúdo de ácidos clorogênicos degradado podem ser encontrados na fração de pigmentos, na forma de ácido quínico livre e como compostos fenólicos de baixa massa molecular (Monteiro e Trugo 2005).

Encontram-se na literatura vários trabalhos associando baixa qualidade do café às concentrações totais de ácidos clorogênicos (Franca et al., 2005; Menezes, 1990; Carvalho et al., 1994), especialmente com relação à concentração de 5-CQA. No entanto, Farah et al. (2006) verificaram que as concentrações do ácido 3,4 dicafeoilquínico do café cru e torrado correlacionaramse positivamente com a qualidade, enquanto grãos defeituosos (verdes, ardidos e brocados) e outros ácidos cafeoilquínicos, especialmente o ácido 5-cafeoilquínico, correlacionaram-se negativamente com a qualidade. Os autores encontraram oito ácidos clorogênicos nos grãos. Os ácidos cafeoilquínicos foram responsáveis por $83 \%$ dessa fração nos grãos crus. A maior concentração desses ácidos correlacionou-se com a pior qualidade, porém sua perda chega a $93 \%$ com torra escura. Houve forte correlação negativa entre ácidos clorogênicos monoésteres e tipo de bebida. Nos grãos crus, o 5-CQA e 5-FQA correlacionaram-se com baixa qualidade da bebida. As concentrações de 4-CQA, 5-CQA, 4-FQA e 5FQA correlacionaram-se fortemente com sabor riado. Em contraste, 3,4-di, CQA e, em menor grau, o 3,5di,CQA, correlacionaram-se com bebida de boa qualidade. Há que considerar ainda, que Menezes (1990) observou uma relação inversa entre concentrações de CQA e maturação. Nesse trabalho, foi observado que os grãos verdes e pretos-verdes têm concentrações mais elevadas de ácidos clorogênicos totais, principalmente CQA e FQA, comparativamente aos maduros e pretos.

\section{Polifenoloxidase}

A polifenoloxidase (PPO) é uma enzima cúprica ligada às membranas celulares. Em condições adversas, ou quando as células do fruto sofrem danos, a PPO atua sobre os polifenóis intra e extracelulares, promovendo hidroxilação de monofenóis a o-difenóis, os quais sofrem remoção de $\mathrm{H}^{+}$e originam o-quinonas, que, por sua vez, inibem a PPO. Assim, grãos que sofreram danos apresentarão baixa atividade da polifenoloxidase, bem como aqueles com deficiência de cobre. A atividade da PPO, fortemente influenciada pelo metabolismo de fenóis, correlaciona-se significativamente com a qualidade da bebida, sendo que a atividade decresce da melhor para a pior qualidade (Amorim \& Silva, 1968). Carvalho et al. (1994) relacionaram os seguintes valores de PPO a diferentes paladares da bebida: "riado" e "rio" - < $55,99 \mathrm{U} \mathrm{g}^{-1}$ de amostra; "duro" - 55,99 a 62,99 U g ${ }^{-1}$ de amostra; "mole" - 62,99 a 67,66 U g-1 de amostra e "estritamente mole" > 67,66 $\mathrm{U} \mathrm{g}^{-1}$ de amostra. 


\section{Índice de coloração}

Quanto ao Índice de coloração, de acordo com Farah et al. (2006) os piores cafés foram os mais escuros. Esse efeito foi atribuído à maior percentagem de grãos defeituosos nos piores cafés e à ação indireta da PPO sobre os compostos fenólicos dessas amostras. O substrato principal para a polifenoloxidase seria o 5CQA, então as ortoquinonas, formadas pela ação da polifenoloxidase sobre o 5-CQA, seriam responsáveis pelo escurecimento. Já nas pesquisas desenvolvidas por Carvalho et al. (1994), Leite \& Carvalho (1994), Chagas et al. (1996), Silva et al. (2002) e Silva et al. (2009), os cafés de melhor qualidade apresentaram maior atividade da PPO e IC. Carvalho et al. (1994) estabeleceram que cafés com índices de coloração iguais ou superiores a 0,65 enquadram-se nas classes de café "duro", "apenas mole", "mole" e "estritamente mole". Índices de coloração inferiores a 0,65 corresponderiam às classificações "riado" e "rio". No trabalho de Clemente (2010), que estudou a qualidade do café em resposta a nitrogênio e potássio, os melhores cafés foram, também, os mais escuros.

\section{Acidez e pH}

Segundo Siqueira \& Abreu (2006), o pH do grão é um indicativo de eventuais transformações dos frutos de café, como as fermentações indesejáveis, que ocorrem na pré ou na pós-colheita, originando defeitos e, consequentemente, redução do pH e deterioração da bebida.

A acidez do café é dada por ácidos não voláteis, como os ácidos oxálico, málico, cítrico, tartárico e pirúvico e voláteis, como acético, propiônico, valérico e butírico, que são produzidos por rotas endógenas e por fermentações indesejáveis. A acidez resultante dos ácidos málico e cítrico tem efeito desejável na qualidade do café, enquanto aquela resultante dos ácidos acético, lático, propiônico e butírico é indesejável (Chalfoun, 1996). Franca et al. (2005) correlacionaram baixa qualidade à acidez, provavelmente advinda de grãos fermentados. Pinto et al. (2002), estudando os padrões de bebida para preparo de café expresso, observaram que os cafés de bebida inferior, com paladar rio e riado, apresentaram maior acidez que as bebidas de paladar estritamente mole e mole. Sivetz \& Desrosier (1979) indicam que cafés torrados sem amargor ou acidez indesejável apresentam $\mathrm{pH}$ entre 4,9 e 5,2 .

\section{Condutividade elétrica e potássio lixiviado}

Alterações na membrana celular após a secagem podem ser identificadas pela lixiviação de várias soluções citoplasmáticas (Borém et al., 2006) e em análises ultra-estruturais de tecidos após a embebição (Neya et al., 2004).
Resultados de trabalho de Amorim (1978), incluindo grãos de diferentes qualidades e processamentos póscolheita, mostram que a lixiviação de K pode ser usada para avaliar o colapso das membranas e, consequentemente, reduções da qualidade do café.

De acordo com Goulart, et al. (2007), altos valores de lixiviação de $\mathrm{K}$ e de condutividade elétrica são fortes indicadores de danos às membranas e à parede celular. Esses autores associaram a análise de fotomicrografias do endosperma de grãos de café classificados como de bebida mole, dura e rio, com a CE, e verificaram que os grãos de pior qualidade apresentaram maior $\mathrm{CE}$ e menor organização e estruturação celular, concluindo que CE elevada é um forte indicador de danos à membrana e parede celular. Porém, por causa do número e da complexidade dos atributos que afetam a qualidade da bebida, os autores indicam que a CE deve ser usada como complemento, para diferenciar bebidas da mesma classe, sendo pouco indicada como meio único de diferenciação.

\section{Lipídios}

Para Coffea arabica, os teores de lipídios encontram-se entre 12 e 16\% (Clifford \& Wilson, 1985; Mazzafera et al., 1998); porém, valores acima de $17 \%$ já foram medidos. Em C. canephora, a média situa-se em torno de $10 \%$, embora teores tão baixos quanto $7 \%$ tenham sido verificados. Desse montante, de 0,2 a 0,3\% constituem uma camada de cera circundante protetora do grão, rica em 5-hidroxitriptamidas de ácido palmítico, aracnídico e alguns outros. Já, na fração óleo, predominam os ácidos linoleico e palmítico. Essa fração é composta por 70 a $80 \%$ de triacilgliceróis, 0,5 a 2,0\% de ácidos graxos livres, 15 a $19 \%$ de terpenos e entre 1,4 e 3,2\% de esteróis (Vidal, 2001).

Os óleos são importantes precursores do aroma do café. Durante a torra, eles são expelidos para a superfície do grão, formando uma capa que retém os aromas voláteis, os quais são paulatinamente perdidos após a moagem. São, também, extraídos e usados para aromatizar o café solúvel (Mazzafera et al., 1998).

Danos internos e pequenas rupturas podem expor óleos e outros lipídios a oxidação durante o armazenamento, levando à formação de aldeídos voláteis indesejáveis ao sabor (Campos 2010). A degradação dos triacilgliceróis durante o armazenamento leva a aumento da acidez (Vidal 2001). Goulart et al. (2007) verificaram que cafés de melhor qualidade tinham paredes e membranas íntegros, além de maior concentração de lipídios próximos às paredes celulares. Em cafés de qualidade inferior, havia ruptura das paredes e membranas, e os lipídios concentravam-se no centro da célula. 


\section{EFEITO DA NUTRIÇÃO MINERAL NA QUALIDADE DO CAFÉ}

A composição química dos grãos de café é influenciada por fatores genéticos, ambientais e culturais, pelos métodos de colheita, processamento, armazenamento, torra e moagem, que afetam diretamente a qualidade da bebida do café (Mendonça et al., 2005). Em se tratando das condições de manejo, as adubações e o estado nutricional da planta podem influenciar tanto na produção quanto na composição do grão cru e, consequentemente, na qualidade da bebida.

\section{Nitrogênio e Potássio}

$\mathrm{O}$ nitrogênio $(\mathrm{N})$ é o nutriente mais exigido para o crescimento vegetativo e o segundo mais exportado pelos grãos do cafeeiro (Catani \& Moraes, 1958). As exigências em potássio $(\mathrm{K})$ são muito próximas das de $\mathrm{N}$, sendo a maior proporção encontrada em grãos, particularmente na polpa do café (Moraes \& Catani 1964).

A cafeína, pertencente ao grupo das xantinas, contém quatro átomos de $\mathrm{N}$ na molécula (Ikan, 1991). De acordo com Clifford \& Wilson (1985), entre 40 e 50\% do nitrogênio do grão torrado corresponde à cafeína e à trigonelina, de modo que uma redução do teor de cafeína dos grãos de plantas deficientes em N seria esperada. Corroborando essa hipótese, Mazzafera (1999) verificou redução dos teores de cafeína de folhas de plantas jovens, cultivadas em solução nutritiva com omissão de N. Clemente (2010), trabalhando com duas doses de N, uma baixa e uma elevada encontrou maiores teores de cafeína nas folhas índice das plantas cultivadas com a maior dose de N. Entretanto, os grãos obtidos nessas duas condições ou não apresentaram diferenças significativas, ou tiveram teores de cafeína inferiores, nas plantas conduzidas com $\mathrm{N}$ elevado. Esse resultado foi atribuído a efeito de diluição da cafeína na maior quantidade de frutos produzidos pelas plantas submetidas à maior dose de $\mathrm{N}$, já que as plantas cultivadas com baixo $\mathrm{N}$ tiveram produção de frutos $39 \%$ inferior.

Os compostos fenólicos, por sua vez, são compostos aromáticos derivados dos ácidos mevalônico e chiquímico. Os ácidos clorogênicos são os principais compostos fenólicos não voláteis encontrados no café. A formação desses compostos pode derivar de um desvio na rota de síntese da lignina, a partir do ácido pcoumárico, que dá origem ao ácido cafeico e outros fenil propanoides simples. Esses compostos, juntamente com o ácido quínico, originam, por esterificação, os ácidos clorogênicos (Lehninger, 1977). Desse modo, doses elevadas de $\mathrm{N}$ poderiam ativar a rota de síntese de lignina e de compostos intermediários precursores de ácidos clorogênicos. Porém, essa hipótese não foi confirmada por Clemente (2010) que encontrou concentrações de fenóis totais, atividade da PPO e índice de coloração maiores em grãos de plantas cultivadas com baixo $\mathrm{N}$.

Por outo lado, Malta et al. (2003) verificaram que grãos de café beneficiado provenientes de plantas adubadas com diferentes fontes de $\mathrm{N}$ apresentaram resposta quadrática da atividade da PPO ao aumento das doses de N. Doses de 50 e $121 \mathrm{~kg} \mathrm{ha}^{-1}$ de N, nas formas de sulfato e de nitrato de amônio resultaram em maiores atividades da enzima, com redução subsequente em doses mais elevadas. Por outro lado, para o nitrato de potássio, a maior atividade da PPO ocorreu com a maior dose de $\mathrm{N}$ aplicada, ou seja, $320 \mathrm{~kg} \mathrm{ha}^{-1}$, indicando uma possível interação entre $\mathrm{N}$ e $\mathrm{K}$ na resposta à dose de $\mathrm{N}$.

Outro grupo de compostos importantes na definição da qualidade do café são os açúcares, cujo metabolismo é fortemente influenciado pela disponibilidade de potássio. O papel do K no metabolismo de compostos nitrogenados e carboidratos é bastante conhecido. Ele é primordial para a ativação de enzimas nas células, por induzir mudanças na conformação enzimática. Em plantas deficientes de $\mathrm{K}$, ocorrem acúmulo de carboidratos solúveis, decréscimo do conteúdo de amido e acúmulo de compostos nitrogenados solúveis. Isso está relacionado com o alto requerimento de $\mathrm{K}$ para funcionamento de certas enzimas regulatórias, principalmente a piruvato cinase e a fosfofrutocinase. Por outro lado, a sintetase do amido, que catalisa a transferência de glicose para moléculas de amido, é altamente dependente de cátions monovalentes, entre os quais o $\mathrm{K}$ é o mais eficiente (Marschner, 2012). Mazzafera (1999), utilizando a técnica do elemento faltante, em experimento conduzido em solução nutritiva, observou que a deficiência de K promoveu aumentos do teor de cafeína em folhas de café.

Silva et al. (1999) avaliaram o efeito de doses de $\mathrm{K}_{2} \mathrm{O}$ aplicadas nas formas de cloreto de potássio e de sulfato de potássio, variando de 0 a 400 g/cova, na qualidade do café produzido. No primeiro ano de avaliação, o sulfato de potássio proporcionou maior atividade da PPO e, no ano seguinte, verificou-se a mesma tendência para a atividade dessa enzima.

Para minimizar o efeito dos íons acompanhantes do $\mathrm{N}$ e do K nos diferentes fertilizantes, Clemente (2010) estudou o efeito de doses de $\mathrm{N}$ e $\mathrm{K}$ sobre a produção e qualidade do café em sistema hidropônico de subirrigação. A autora realizou um experimento de longa duração em solução nutritiva, conduzindo plantas da variedade Catuaí vermelho IAC 99, sob condições controladas de casa de vegetação até a primeira colheita. Foram empregadas quatro doses de $\mathrm{K}$, combinadas com duas doses de $\mathrm{N}$. Os resultados evidenciaram resposta quadrática às doses de potássio, indicando efeito positivo do nutriente na produção de grãos, teor de cafeína, fenóis totais, 
açúcares totais e redutores, índice de coloração e acidez total titulável. Os valores dessas variáveis aumentaram até atingir um ponto de máximo, a partir do qual o efeito do $\mathrm{K}$ passou a ser deletério, provavelmente por causa do estabelecimento de competição com $\mathrm{Ca}$ e $\mathrm{Mg}$, em doses elevadas de K. Corroborando o efeito positivo do K na qualidade, a condutividade elétrica e lixiviação de potássio foram reduzidas com o aumento das doses de $\mathrm{K}$, até atingirem um ponto de mínimo associado à dose ótima.

Convém destacar que a melhor qualidade sensorial do café foi alcançada em plantas com concentrações foliares de 3,01 dag $\mathrm{kg}^{-1} \mathrm{~N}$ e 2,94 dag $\mathrm{kg}^{-1}$ de $\mathrm{K}$, e que tinham, nessas condições, 2,20 dag $\mathrm{kg}^{-1}$ de $\mathrm{N}$ e 1,82 dag $\mathrm{kg}^{-1}$ de $\mathrm{K}$, nos grãos. A melhor qualidade sensorial foi obtida com doses de K que permitiram obter $98,70 \%$ da produção máxima de café cereja (Clemente, 2010). O N influenciou principalmente as características de crescimento vegetativo, enquanto o $\mathrm{K}$ influenciou principalmente as características de crescimento reprodutivo, como número de frutos do ramo índice, produção e tamanho de grãos (Clemente et al., 2013).

\section{Boro, Cobre e Zinco}

A ordem de acúmulo de micronutrientes em cafeeiro, segundo Catani et al. (1989), é $\mathrm{Fe}>\mathrm{Mn}>\mathrm{B}>\mathrm{Zn}>\mathrm{Cu}>$ Mo. Uma vez que os solos brasileiros em que se assenta grande parte da cafeicultura apresentam teores elevados de Fe e Mn (Furlani Junior et al., 2004) e que o cafeeiro não tem grande exigência de Mo, pode-se compreender por que os micronutrientes $\mathrm{B}, \mathrm{Zn}$ e $\mathrm{Cu}$ são considerados os de maior importância para o crescimento e produção do cafeeiro, sendo também os mais estudados.

Sob deficiência de B, ocorre o acúmulo de fenóis, o que se relaciona com o papel do boro na formação de complexos cis-diol com certos açúcares e fenóis. Nessas condições, o fluxo de substrato é deslocado para o ciclo das pentoses fosfato, aumentando, assim, a biossíntese de fenóis. Em resposta ao acúmulo de fenóis, a atividade da polifenoloxidase aumenta, em tecidos deficientes em B (Lewis, 1980; Loomis \& Durst, 1991; Marschner, 2012), o que, junto com o excesso de fenóis, provoca a destruição da membrana celular e, consequentemente, a morte do tecido vegetal (Marschner, 2012). A polifenoloxidase é uma enzima que, de acordo com vários autores, mostra-se diretamente relacionada com a qualidade da bebida do café (Amorim \& Silva, 1968; Amorim, 1978; Carvalho et al., 1994; Leite, 1991; Pereira, 1997). Esses autores verificaram que ocorre um aumento significativo da atividade da polifenoloxidase, à medida que o café apresenta-se com melhor qualidade e que as variações da atividade enzimática da polifenoloxidase permitem separar as classes de bebida.
Clemente (2014) estudou o efeito do B na produção de grãos, qualidade da bebida e produção de compostos bioativos em grãos crus de café, em experimento realizado numa lavoura adulta de $C$. arabica, cv. Catuaí Vermelho IAC 99. Houve efeito positivo desse nutriente nos teores de cafeína, trigonelina, sacarose, glucose e atividade da PPO. 3-CQA e 5-CQA tiveram suas concentrações reduzidas com a disponibilização de B, enquanto 4-CQA, proantocianidinas e fenóis totais não responderam ao seu fornecimento. Acompanhando-se os teores de $\mathrm{B}$ das folhas índice nos diferentes tratamentos, verificou-se que tanto a falta quanto o excesso de B reduziram a síntese de cafeína e trigonelina. Foi observado, ainda, que as concentrações foliares de B, associadas a um bom crescimento e produção, estão abaixo daquelas que maximizam a atividade da PPO, característica que tem sido fortemente associada à qualidade da bebida.

Vários trabalhos na literatura relatam o acúmulo de ácidos cafeoilquínicos em deficiência de B. CamachoCristobal et al. (2004) reportam que a deficiência de B leva ao acúmulo de glucose, frutose e amido, seguido por aumento da concentração de 3-CQA, 4-CQA e 5CQA em folhas de tabaco. Os autores atribuíram esse efeito ao aumento da atividade da fenilalanina amônia liase e ao consequente aumento da síntese de fenóis.

O cobre beneficia as plantas por meio do seu efeito como micronutriente, como fungistático e como tonificante. Esse micronutriente é essencial às plantas por ser componente de muitas enzimas e proteínas e por estar envolvido em inúmeras rotas metabólicas. Várias enzimas, que contêm ou são ativadas pelo $\mathrm{Cu}$, catalisam reações de óxido-redução (Marschner, 2012). Além disso, o $\mathrm{Cu}$ pode exercer efeitos diretos ou indiretos sobre fungos. Como efeito direto, a influência desse micronutriente está relacionada com a sua capacidade fungistática, desnaturando proteínas do patógeno. Indiretamente, sua participação é importante na síntese de lignina, que age como barreira à penetração de microorganismos (Pasin et al., 2002). Desta forma, o uso do cobre, melhora o desenvolvimento e a produtividade dos cafezais e beneficia, ainda, a qualidade dos grãos de café.

Lacerda (2014) realizou um experimento em casa de vegetação, usando sistema hidropônico, com areia como substrato, para verificar o efeito de doses crescentes de $\mathrm{Cu}\left(0,2 ; 0,4 ; 0,8 ; 1,6\right.$ e $\left.3,2 \mu \mathrm{mol} \mathrm{L}^{-1}\right)$ na concentração de compostos relacionados com a qualidade nos grãos crus de café. Após três anos de condução, o autor verificou que as doses de $\mathrm{Cu}$ influenciaram positivamente produção de grãos, atividade da PPO, e teores de sacarose e, negativamente, as concentrações de fenóis totais, 5-CQA e 4-CQA. As variáveis atividade da enzima PPO, produção de grãos e concentração de sacarose aumentaram com as doses de $\mathrm{Cu}$ até atingir um ponto de máximo, 
decrescendo em seguida. Inversamente, fenóis totais, 4CQA e 5-CQA decresceram até um ponto de mínimo, com posterior incremento com as doses de $\mathrm{Cu}$. O 3CQA, ao contrário do esperado, aumentou com as doses de $\mathrm{Cu}$ até atingir o ponto de máximo, declinando a seguir. $\mathrm{O}$ ponto de máximo estimado para a concentração de 3-CQA foi muito próximo do ponto de máximo da atividade da PPO, sugerindo um efeito positivo do 3CQA na qualidade. É provável que o acúmulo de 3-CQA limite as concentrações de 4-CQA e principalmente do 5-CQA, principal substrato para a PPO, e fortemente associado à perda da qualidade da bebida. Cafeína, trigonelina, K lixiviado e análise sensorial não apresentaram variações significativas com as doses de $\mathrm{Cu}$.

Doses entre 1,45 e $2,59 \mu \mathrm{mol} \mathrm{L} \mathrm{L}^{-1}$ de $\mathrm{Cu}$ permitiram otimizar a produção e diversas características relacionadas com a qualidade. Nessas condições, os teores de $\mathrm{Cu}$ nas folhas índice estiveram entre 7,20 e 11,37 mg $\mathrm{kg}^{-1}$, ou seja, abaixo da faixa de nutrição adequada proposta por Martinez et al. (2003), que se situa entre $13 \mathrm{e}$ $29 \mathrm{mg} \mathrm{kg}^{-1}$. Cabe aqui salientar que as faixas de suficiências descritas por Martinez et al. (2003) foram estabelecidas com base em lavouras produtivas e que plantas cultivadas a campo, possivelmente, apresentem $\mathrm{Cu}$ retido na cutícula ou superfície foliar, de difícil lavagem, o que não ocorre em condições controladas de casa de vegetação. Corroborando os resultados acima descritos, em experimento de campo, Clemente (2014) obteve efeito positivo do $\mathrm{Cu}$ nas concentrações de cafeína, trigonelina, sacarose, glicose e PPO. Para 3-CQA e 5-CQA, o efeito foi negativo, havendo clara relação inversa entre a atividade da PPO e a concentração de 5CQA.

Quanto ao Zn, baixos teores desse elemento em cafeeiros podem afetar mais o desenvolvimento reprodutivo do que o vegetativo (Fávaro, 1992). A carência de Zn pode provocar a diminuição da produção de sementes (Malavolta et al., 1997; Mengel \& Kirkby, 1987), que pode estar relacionada com o menor desenvolvimento das anteras e com a inviabilidade dos grãos de pólen quando a planta está sob deficiência deste elemento (Sharma et al., 1987; Sharma et al., 1990). Alguns relatos confirmam a importância do Zn na produção de grãos (Silva, 1979; Fávaro, 1992). Mello et al. (1999) verificaram que o cafeeiro respondeu às aplicações de doses crescentes de sulfato de zinco, por via foliar, na produção, e que o aumento das doses de $\mathrm{Zn}$ proporcionou maior percentagem de grãos classificados nas maiores peneiras. Os grãos de café retidos em peneiras com crivos de maior diâmetro, associados a outros aspectos de boa qualidade, geralmente apresentam maior valor no mercado. A separação pelo tamanho dos grãos, por meio da classificação por peneiras, proporciona melhor quali- dade do produto final, resultando mais uniformidade na torra (Nasser \& Chalfoun, 2000). Neves et al., (2011) observaram que o fornecimento de $\mathrm{Zn}$ influenciou positivamente a produção e a qualidade dos grãos de café, caracterizada pelo seu tamanho, percentagem de grãos brocados, condutividade elétrica e o potássio lixiviado dos grãos. Os resultados de Martinez et al. (2013) corroboraram os anteriores e indicaram, ainda, que os grãos de cafeeiros supridos com $\mathrm{Zn}$ apresentaram maiores teores de ácidos clorogênicos e maior atividade antioxidante.

$\mathrm{O}$ efeito do $\mathrm{Zn}$ sobre os compostos químicos relacionados com a qualidade da bebida nos grãos crus foi estudado por Lacerda (2014). O autor forneceu doses de Zn $\left(0,2 ; 1,0 ; 2,0 ; 3,0\right.$ e 4,0 $\left.\mu \mathrm{mol} \mathrm{L}^{-1}\right)$ a plantas de café cultivadas por três anos em vasos de $20 \mathrm{~L}$, contendo areia, irrigados com solução nutritiva, em sistema hidropônico de gotejamento. Houve resposta quadrática crescente às doses de Zn para atividade da PPO, índice de coloração, concentração de cafeína, trigonelina, sacarose, arabinose, manose, ácido cítrico e ácido tartárico nos grãos. Após os pontos de máximo estimados, que ocorreram nos grãos de plantas que apresentavam teores de $\mathrm{Zn}$ entre 9,73 e 10,27 $\mathrm{mg} \mathrm{kg}^{-1}$ nas folhas índice, houve declínio da concentração desses compostos. Já acidez titulável, pH, fenóis totais, 5-CQA, 4-CQA, potássio lixiviado e condutividade elétrica apresentaram resposta quadrática decrescente ao $\mathrm{Zn}$, com pontos de mínimo em grãos de plantas que apresentavam teores de $\mathrm{Zn}$ entre 9,73 e 9,90 $\mathrm{mg} \mathrm{kg}^{-1}$ nas folhas índice.

Também neste caso, 3-CQA apresentou resposta inversa às de 4-CQA e 5-CQA, com ponto de máximo em concentração de $\mathrm{Zn}$ muito próxima da que resultou em máxima atividade da PPO. Fica evidente que, de modo geral, as concentrações dos compostos relacionados positivamente com a qualidade da bebida foram maximizadas e a dos negativamente relacionados com a qualidade da bebida foram minimizadas quando as plantas apresentavam teores foliares de $\mathrm{Zn}$ dentro da faixa de nutrição adequada, proposta por Martinez et al. (2003), entre 8 e $12 \mathrm{mg} \mathrm{kg}^{-1}$. Chama a atenção, entretanto, que essas condições não foram as que resultaram em maior produção de grãos. A maior produção de grãos foi obtida com a menor dose de Zn empregada, de 0,2 $\mu$ mol $\mathrm{L}^{-1}$, enquanto os atributos positivamente relacionados com a qualidade foram máximos e os negativamente relacionados com a qualidade foram mínimos, com doses entre 1,3 e 2,2 $\mu \mathrm{mol} \mathrm{L}{ }^{-1}$ de $\mathrm{Zn}$.

Embora não se tenha verificado diferença estatística para a análise sensorial, verificou-se que a menor dose de $\mathrm{Zn}\left(0,2 \mu \mathrm{mol} \mathrm{L} \mathrm{L}^{-1}\right)$ resultou em bebida dura, enquanto as doses mais elevadas resultaram em bebida mole. Também neste caso, os resultados obtidos em campo por 
Clemente (2014), com relação ao efeito do Zn sobre as concentrações de cafeína, trigonelina, sacarose, glucose, 5-CQA e fenóis totais confirmam os de Lacerda (2014).

Ainda com relação aos micronutrientes, Pasin et al. (2002) verificaram que pulverizações de $\mathrm{Cu}, \mathrm{Zn}, \mathrm{Mn}$ e B diretamente sobre os frutos durante seu desenvolvimento reduziram significativamente a percentagem média de incidência de Aspergillus ochraceus, Fusarium semtectum, Cladosporium cladosporioides, sem afetar significativamente a ocorrência de Penicillium variable.

Considerando-se os resultados obtidos sob os efeitos de $\mathrm{B}, \mathrm{Cu}$ e $\mathrm{Zn}$ na produção de compostos relacionados com a qualidade do café e, também, seu aparente papel na redução de infecções por fungos toxicogênicos, o manejo da nutrição com micronutrientes parece ser uma forma promissora de se obter um produto de melhor qualidade.

Convém salientar, entretanto, que nos trabalhos relacionando nutrição mineral com qualidade da bebida, aqui apresentados, foram empregados frutos maduros submetidos a condições de pós-colheita adequadas. Nessas condições, não se obtiveram classificações "riado" ou "rio" em nenhuma circunstância, o que reforça a importância principal da pós-colheita na qualidade da bebida do café.

\section{REFERÊNCIAS}

Aguiar ATE (2005) Atributos químicos de espécies de café. Tese de Doutorado. Escola Superior de Agricultura "Luiz de Queiroz", Piracicaba. 87p.

Ashihara H (2006) Metabolism of alkaloids in coffee plants. Brazilian Journal of Plant Physiology, 18:1-8.

Alves E (1996) População fúngica associada ao café (Coffea arabica) beneficiado e às fases de pré e pós-colheita - Relação com a bebida e local de cultivo. Dissertação de Mestrado. Universidade Federal de Lavras, Lavras. 49p.

Alves E (2009) Variabilidade espacial e temporal da qualidade do café cereja produzido na região das Serras de Minas. Tese de Doutorado. Universidade Federal de Viçosa, Viçosa. 122p.

Amorim VH (1978) Aspectos bioquímicos do grão de café verde relacionados com a deterioração da qualidade. Tese de Livre Docência. Escola Superior de Agricultura "Luiz de Queiroz", Piracicaba. 85p.

Amorim VH \& Silva DM (1968) Relationships between the polyfenol oxidase activity of coffee beans and the quality of the beverage. Nature, 219:381-382.

Borém FM, Ribeiro DM, Pereira RGFA, Rosa SDVF \& Morais AR (2006) Qualidade do café submetido a diferentes temperaturas, fluxos de ar e períodos de pré-secagem. Coffee Science, 1:55-63.

Brasil - Ministério da Agricultura, Pecuária e Abastecimento (2003) Regulamento técnico de identidade e de qualidade para a classificação do café beneficiado grão cru. Instrução Normativa ${ }^{\circ} 8$, de 11 de junho de 2003

Camacho-Cristobal JJ, Lunar L, Lafont F, Baumert A \& Gonzales-Fontes A (2004) Boron deficiency causes accumulation of chlorogenic acid and caffeoyl polyamine conjugates in tobacco leaves. Journal of Plant Physiology, 161:879-881.
Campos SC (2010) Uso da morfometria celular na análise da qualidade de grãos de café nas etapas do processamento via úmida e durante o armazenamento. Tese de Doutorado. Universidade Federal de Viçosa, Viçosa. 90p.

Carvalho VD (1997) Cafeicultura empresarial: produtividade e qualidade - qualidade do café. Monografia. Universidade Federal de Lavras, Lavras. 73p.

Carvalho VD \& Chalfoun SM (1985) Aspectos qualitativos do café. Informe agropecuário, 11:79-92.

Carvalho VD, Chagas SJR, Chalfoun SM, Botrel N \& Juste Junior ESG (1994) Relação entre a composição físico-química e química do grão beneficiado e a qualidade de bebida do café. I. Atividades de polifenoloxidase e peroxidase, índice de coloração de acidez. Pesquisa Agropecuária Brasileira, 29:449-454.

Catani RA \& Moraes FRP (1958) A composição química do cafeeiro. Revista de agricultura, 33:45-52.

Catani RA, Pellegrino D, Bittencourt VC, Jacintho AO \& Graner CAF (1989) A concentração e a quantidade de micronutrientes e de alumínio no cafeeiro aos dez anos de idade. Anais da Escola Superior de Agricultura Luiz de Queiróz, 46:403-431.

Chagas SJR (1994) Caracterização química e quantitativa de cafés de alguns municípios de três regiões produtoras de Minas Gerais. Tese de Mestrado. Universidade Federal de Lavras, Lavras. 83p.

Chagas SJ de R, Carvalho VD \& Costa L (1996) Caracterização química e qualitativa de cafés de alguns municípios de três regiões produtoras de Minas Gerais. II. Valores de acidez titulável e teores de açúcares (redutores, não redutores e totais). Ciência e Agrotecnologia, 20:224-231.

Chalfoun SMS (1996) O café (Coffea arabica L.) na Região Sul de Minas Gerais - relação da qualidade com fatores ambientais, estruturais e tecnológicos. Tese de Doutorado. Universidade Federal de Lavras, Lavras. 171p.

Cheynier V (2005) Polyphenols in foods are more complex than often thought. The American Journal of Clinical Nutrition, 81:223-229.

Clemente JM (2010) Efeito de NK na qualidade da bebida do café. Dissertação de Mestrado. Universidade Federal de Viçosa, Viçosa. 52p.

Clemente JM (2014) Boron, copper and zinc effects on photosynthesis, enzymatic activity, nutritional status, production, chemical composition and cup quality of coffee. Tese de Doutorado. Universidade Federal de Viçosa, Viçosa. 115p.

Clemente JM, Martinez HEP, Alves LC \& Lara MCR (2013) Effect of N and $\mathrm{K}$ doses in nutritive solution on growth, production and coffee bean size. Revista Ceres, 60:279-285.

Clifford MN \& Wilson KC (1985) Coffee: Botany, biochemistry and production of beans beverage. New York, Croom Helm. 457p.

Dalvi LP (2011) Rendimento e Qualidade do Café Colhido no Estádio Verde-Cana e Preparado por Via Úmida. Tese de Doutorado. Universidade Federal de Viçosa, Viçosa. 58p.

Farah A, Monteiro MC, Calado V, Franca AS \& Trugo LC (2006) Correlation between cup quality and chemical attributes of Brazilian coffee. Food Chemistry, 98:373-380.

Fávaro JRA (1992) Crescimento e produção de Coffea arabica L. em resposta a nutrição foliar de zinco na presença de cloreto de potássio. Dissertação de Mestrado. Universidade Federal de Viçosa, Viçosa. $91 \mathrm{p}$.

Franca AS, Oliveira LS, Mendonça JCF \& Silva XA (2005) Physical and chemical attributes of defective crude and roasted coffee beans. Food Chemistry, 90:84-89.

Furlani Junior E, Alves CC, Lazarini E \& Ferrari S (2004) Aplicação de calcário e boro em cafeeiro (Coffea arabica L.). Cultura Agronômica, 13:1-25. 
Goulart PFP, Alves JD, Castro EM, Fries DD, Magalhães MM \& Melo HC (2007) Aspectos histoquímicos e morfológicos de grãos de café de diferentes qualidades. Ciência Rural, 37:662-666.

Ikan R (1991) Natural Products: A Laboratory Guide. New York, Harcourt Brace Jovanovich Publishers. 226p.

Lacerda JS (2014) Produção, composição química e qualidade da bebida de café arábica em razão da dose de cobre e zinco. Tese de doutorado. Universidade Federal de Viçosa, Viçosa. 97p.

Lehninger AL (1977) Bioquímica. São Paulo, Edgard Blucher. 770p.

Leite IP (1991) Influência do local de cultivo e do tipo de colheita nas características físicas, composição química do grão e qualidade do café (Coffea arabica L.). Dissertação de Mestrado. ESAL, Lavras. 135p.

Leite IP \& Carvalho VD (1994) Influência do local de cultivo e do tipo de colheita nas características físicas, composição química do grão e qualidade do café. Pesquisa Agropecuária Brasileira, 29:299-308.

Leroy T, Ribeyre F, Bertrand B, Charmetant P, Dufour M, Montagnon C, Marraccini P \& Pot D (2006) Genetics of coffee quality. Brazilian Journal of Plant Physiology, 18:229-242.

Lewis DH (1980) Boron, lignification and the origin of vascular plants a unified hypothesis. New Phytologist, 84:209-229.

Loomis WD \& Durst RW (1991) Boron And Cell Walls. In: Randall DD, Blevins DG \& Miles CD (Eds.) Current Topics in Plant Biochemistry and Physiology. Columbia, University of Missouri. p.149-178.

Malavolta E, Vitti GC \& Oliveira AS (1997) Avaliação do estado nutricional das plantas: princípios e aplicações. $2^{\mathrm{a}}$ ed. Piracicaba, Potafos. 319p

Malta MR, Nogueira FD, Guimarães PTGG \& Silva FAM (2003) Composição química, produção e qualidade do café fertilizado com diferentes fontes de nitrogênio. Ciência e Agrotecnologia, 27:1246-1252.

Manach C, Scalbert A, Morand C, Rémésy C \& Jiménez L (2004) Polyphenols: food sources and bioavailability. The American Journal of Clinical Nutrition, 79:727-747.

Marschner P (2012) Marschner's mineral nutrition of higher plants. $3^{\mathrm{a}} \mathrm{ed}$. New York, Academic Press. 651p.

Martinez HEP, Menezes JFS, Souza RB, Alvarez-Venegas VH \& Guimarães PTG (2003) Faixas críticas de concentrações de nutrientes e avaliação do estado nutricional de cafeeiros em quatro regiões de Minas Gerais. Pesquisa Agropecuária Brasileira, 38:703-713.

Martinez HEP, Poltronieri Y, Farah A \& Perrone D (2013) Zinc supplementation, production and quality of coffee beans. Revista Ceres, 60:293-299.

Mazzafera P (1999) Mineral nutrition and caffeine content in coffee leaves. Bragantia, 58:387-391.

Mazzafera P, Soave D, Zullo MAT \& Filho OG (1998) Oil Content of green beans from some coffee species. Bragantia, 57:45-48.

Mello EM, Guimarães PTG, Silva EB \& Nogueira FD (1999) Efeito da aplicação foliar de sulfato de zinco na produção do cafeeiro (Coffea arabica L.). Ciência e Agrotecnologia, 23:84-95.

Mendonça LMVL, Pereira RGFA \& Mendes ANG (2005) Parâmetros bromatológicos de grãos crus e torrados de cultivares de café (Coffea arabica L.). Ciência e Tecnologia de Alimentos, 25:239-243.

Menezes HC (1990) Variação dos monoisômeros e dos diisômeros do ácido cafeoil quínico com a maturação de café. Tese de Doutorado. Universidade Estadual de Campinas, Campinas. 95p.

Mengel K \& Kirkby EA (1987) Principles of plant nutrition. 4aed. Berna, Internacional Potash Institute. 687p.

Monteiro MC \& Trugo LC (2005) Determinação de compostos ativos em amostras comerciais de café torrado. Química Nova, 28:637-641.

Moraes FRP \& Catani RA (1964) A absorção de elementos minerais pelo fruto do cafeeiro durante sua formação. Bragantia, 23:331-336.
Nasser PP \& Chalfoun SM (2000) Eficiência da separação de grãos de café de acordo com o tamanho dos grãos de café na análise da qualidade da bebida pelo método químico. In: $1^{\circ}$ Simpósio de Pesquisas dos Cafés do Brasil, Poços de Caldas. Resumos expandidos. Brasília, Embrapa Café/ MINASPLAN. p.737-739.

Neves YP, Martinez HEP \& Cecon PR (2011) Effect of zinc and its form of supply on production and quality of coffee beans. Journal of the Science of Food and Agriculture, 91:2431-2436.

Neya O, Golovina EA, Nijasse J \& Hoekstra FA (2004) Ageing increases the sensitivity of neem (Azadirachta indica) seeds to imbibitional stress. Seed Science Research, 14:205-217.

Pasin LAAP, Abreu MS, Souza SMC \& Pádua TRP (2002) Efeito de micronutrientes na população fúngica associada a grãos de café (Coffea arabica L.). Ciência e Agrotecnologia, 26:918-926.

Pereira RGFA (1997) Efeito da inclusão de grãos defeituosos na composição química e qualidade do café (Coffea arabica L.) "estritamente mole". Tese de Doutorado. Universidade Federal de Lavras, Lavras. 94p.

Pinto NAVD, Fernandes SM, Giranda RN, Pereira RRGF \& Carvalho VD (2002) Avaliação de componentes químicos de padrões de bebida para o preparo de café expresso. Ciência e Agrotecnologia, 26:826-829.

Pozza AAA, Guimarães PTG, Carvalho VL, Pozza EA, Carvalho JG \& Romaniello MM (2004) Interações entre as doenças e estado nutricional do cafeeiro. Lavras, EPAMIG. 84p. (Boletim técnico, 73).

Rodrigues JD \& Ono EO (2001) Na hora certa. Cultivar Grandes Culturas, 30:32-34

Sharma PN, Chatterjee C, Agarwala SC \& Sharma CP (1990) Zinc deficiency and pollen fertility in maize (Zea mays). Plant and Soil, 124:221-225.

Sharma PN, Chatterjee C, Sharma CP \& Agarwala SC (1987) Zinc deficiency and anther development in maize. Plant and Cell Physiology, 28:11-18.

Silva EB, Nogueira FD \& Guimarães PTG (2002) Qualidade dos grãos de café em função de doses de potássio. Acta Scientiarum, 24:1291-1297.

Silva EB, Nogueira FD, Guimarães PTG, Chagas SJR \& Costa L (1999) Fontes e doses de potássio na produção e qualidade do grão de café beneficiado. Pesquisa Agropecuária Brasileira, 34:335-345.

Silva JBS (1979) Influencia de doses de sulfato de zinco, aplicadas por via foliar, sobre a produção do cafeeiro. Dissertação de Mestrado. ESAL, Lavras. 62p.

Silva MC da, Castro HAO, Farnezi MMM, Pinto NAVD \& Silva EB (2009) Caracterização química e sensorial de cafés da Chapada de Minas, visando determinar a qualidade final do café de alguns municípios produtores. Ciência e Agrotecnologia, 33:1782-1787.

Simões RO (2009) Qualidade do café (Coffea arabica L.) pré-processado por via seca. Dissertação de Mestrado. Universidade Federal de Viçosa, Viçosa. 121p.

Simões RO, Faroni LRD \& Queiroz DM (2008) Qualidade dos grãos de café (Coffea arabica L.) em coco processados por via seca. Caatinga, 21:139-146.

Siqueira HH \& Abreu CMP (2006) Composição físico-química e qualidade do café submetido a dois tipos de torração e com diferentes formas de processamento. Ciência e Agrotecnologia, 30:113-116.

Sivetz M \& Desrosier NW (1979) Coffee Technology. Westport, AVI Publishing Company. 716p.

Taiz L \& Zeiger E (2004) Fisiologia Vegetal. $3^{\mathrm{a} e d . ~ P o r t o ~ A l e g r e, ~ A r t m e d . ~}$ 719 p.

Vargas-Elias GA (2011) Avaliação das propriedades físicas e qualidade do café em diferentes condições de torrefação. Dissertação de Mestrado. Universidade Federal de Viçosa, Viçosa. 98p.

Vidal HM (2001) Composição lipídica e a qualidade do café (Coffea arabica L.) durante armazenamento. Dissertação de Mestrado. Universidade Federal de Viçosa, Viçosa. 93p. 